and arts regardless of the relations of these to a constantly shifting industrial situation.

Perhaps there may exist other reasons than those here considered which render desirable the rewriting of the constitution. It appears to the writer, however, to be the part of wisdom to adhere in any revision, and particularly in one undertaken at the present time, to the idea of a strictly guarded constitutional basis for all activities of the society, with the least possible allowance of latitude in the administration of this organic law. Should it be found upon investigation in detail that under present conditions a serious handicap is encountered through the existing method of amending the constitution, this could, to a large extent at least, be overcome by shortening the period in which a proposed amendment could be acted upon, that period being approached as nearly as can be to the time that at present is required to make a new by-law by action of the Board of Directors.

Though aside from the main object of this communication, reference might here be made to the desirability, on the grounds of professional propriety, of the elimination, in any future revision

\section{Engineering and Efficiency*}

By H. G. StotT

Engineering has been defined by Tredgold as " the art of directing the great sources of power in nature for the use and convenience of man."

Efficiency may be defined as the art of obtaining the maximum output from the minimum input.

With these two definitions in mind, we will proceed to analyze the relations between the two, keeping in touch as much as possible with the work of our own times.

If we take our own branch of engineering, we will find that in its brief career of thirty years it has already been

*Presented before the Schenectady Section. A. I. E. E., December 4,1912 . of the constitution, of such industrial corporation appendages as "General Counsel" and "Law Committee." The Institute is little more than a corporation by courtesy, and in fact was incorporated only to acquire a legal status as a property owner. Such appendages of industrial and commercial corporations engaged in the fierce battle for dollars, serve, in the best sense, for the protection of their rights or, in the worst sense, for infringement on the rights of others; on the other hand, the Institute is subject to no menace against its constitutional purposes, and does not, of course, desire to profit from legal technicality in its conduct. On rare occasions, when it may be actually desirable to obtain legal advice, this could be secured in the same manner as when a professional man feels he should consult a lawyer. If the former more dignified and appropriate name of "Council" were substituted for " Board of Directors," the professional impropriety of the present legal adjuncts to the government of the Institute would stand out still more clearly.

Charlottesville, Va.,

W. D. Weaver

December 30, 1912

subdivided into at least twenty distinct divisions.

Some of these branches of engineering do not make any claim to exist for the purpose of developing higher efficiency in the strictest sense of the word, but do exist for convenience, and owing to their convenience they have now become necessities.

Take telegraphy, for example; it is difficult (if we follow Tredgold's definition of engineering) to see any connection between telegraphy and efficiency, as we have defined it; and the same argument applies to telephony and many other branches of general engineering, such as sanitation, surveying and military engineering, etc.

We have all become so accustomed to 
the use of the word "efficient" that instinctively we feel that, whilst the above illustrations may be true, yet per se these various branches of engineering may be carried on in a more or less efficient manner. This instinctive feeling is a recognition of the fact that our original definition of engineering was lacking in that it ignored the economic factor which now plays such an important part in the engineer's work.

The moment we recognize the economic factor, we immediately see that telegraphy and telephony are most highly efficient, as they save enormous amounts of time, and it is probably no exaggeration to say that the average business man's efficiency has been improved at least 10 per cent by their use, which virtually means that a man now can accomplish as much in ten years as he formerly did in eleven, when the telephone and telegraph did not exist. In the same way, the work of the sanitary engineer has resulted in opening up parts of the world which were formerly so deadly in character as to be almost impossible for the white races. Notable instances of this are the work of our sanitary engineers in Cuba and the Isthmus of Panama, which were formerly scourged by yellow fever and malaria; but now, thanks to the engineer's work, they are almost as healthy as our northern states.

There is another instance where the economic factor enters again; for the efficiency of the whole world is increased a little when we open up new territory for habitation by the human race.

The company with which the speaker is connected has been engaged in important work, which has also resulted in greatly increased efficiency through the use of sound engineering principles; and as many novel problems were encountered, a brief sketch of the more important may prove interesting.

The existing New York subway system was designed to carry a maximum of 400,000 passengers per day; but the growth of the city was so rapid that some means had to be taken to relieve the intolerable congestion of the system. As a result of careful study, it was decided to lengthen the station platforms so as to accommodate six-car local trains and ten-car expresses in place of the original five- and eight-car trains. This, in itself, was no small problem, as traffic had to be maintained whilst all this construction work was going on; but fortunately this difficult feat in engineering was accomplished without accident.

Ten-car trains were run experimentally and it soon developed that numerous new problems were to be solved by the car equipment department. Cars which formerly behaved in a decorous manner developed alarming characteristics of the broncho when coupled in tens, and refused to stay hitched together when accelerating or retarding. Further study developed the fact that the standard form of draft gear was no longer suited to handle multiple-unit trains of the weight and power used in the subway, and that instead of having the usual lost motion between cars, it was essential that there be no lost motion. This meant the design of pneumatic draft gear of a novel type, which successfully met the requirement of no lost motion.

During the period of retardation the ten-car trains had also broken apart and a careful examination of the facts showed that the brakes were not being applied synchronously on all the cars, due to the time lag of the air in the train line. Electricity was brought into play at this point and a new type of electrically operated air valve was developed and substituted for the old air line, with highly satisfactory results.

The introduction of pneumatically operated center side doors gave rise to many difficult problems in the redesign of the original cars, but all these were successfully overcome.

In order to reduce the length of the stops at the station, a new system of signalling to the motorman was developed; all the doors were equipped with a simple and sturdy type of circuit switch 
and all these switches were connected in series through a bell in the motorman's cab. This accomplishes a twofold purpose; first, giving the starting signal to the motorman the moment the doors are closed, and second, making sure that the train will not be started until all the doors are closed.

It also became imperative to shorten the interval between trains and this was accomplished by a re-arrangement of the signal system such as to permit an interval of less than three minutes, as originally operated.

In the motive power department we were confronted with a number of problems which called for solution in order to provide power for the operation of the additional cars and trains.

The low-tension feeder system was largely reinforced, and at points midway between substations circuit breakers were installed between each of the four contact rails and a common bus, so as to parallel the third rails and thus get the benefit of the conductivity of all the feeders to reduce the momentary drop during the brief periods of acceleration of the ten-car trains, when each one takes about $2600 \mathrm{kw}$. These tie-in circuit breakers are operated by air pressure and are controlled from the adjacent substations; being interlocked with feeder circuit breakers, each track can be isolated from the substation switchboard at a moment's notice, thus giving great flexibility to the low-tension system.

The substations had been designed so as to accomodate six or eight 1500 kw. synchronous converters, and as more power was required the problem was either how to get more converters in, or else how to install larger machines in the same space occupied by the 1500 $\mathrm{kw}$. units. The first alternative was possible in some of the substations, but not in others, so the manufacturer was called in and requested to design as large a converter as the space would permit. This resulted in the development of a $3000-\mathrm{kw}$. unit and later, of an interpole converter capable of carrying a load of
$4500 \mathrm{kw}$. for three hours and 10,000 $\mathrm{kw}$. for one minute.

Toillustrate the progress of the art, we can now obtain a unit which will occupy the same floor space as the original $1500-\mathrm{kw}$. machine, but with a steady rating of over $6000 \mathrm{kw}$. and $12,000-\mathrm{kw}$. rating for thirty seconds.

In the power plant it also became necessary to get additional capacity and several alternatives were considered, amongst them being the installation of the regular high-pressure turbine as a prime mover. If this course had been adopted, the existing highgrade engine-driven units would have been disposed of at the price of scrap, but fortunately an alternative in the shape of a low-pressure turbine was available, and this type of unit was installed in connection with five of the engine-driven units. The installation of these low-pressure machines resulted in some very important economies; first, they gave a new lease of life to their partners, the reciprocating units; second, they gave an increase of $\mathbf{1 0 0}$ per cent in the maximum capacity of the plant; third, an increase of 146 per cent in the economic capacity, and lastly, but not least, an improvement of 25 per cent in economy of the plant.

The result of all these improvements in the system was that the subway had the interval between trains cut down from three minutes to one minute and forty-eight seconds, or an improvement of 40 per cent; and the daily capacity was increased from 400,000 passengers to over $1,000,000$ at the same time. This is surely an illustration of the relationship between engineering and efficiency.

However, we should not feel too much pride in our achievements, as a moment's consideration of the losses going on will speedily restore us to a feeling of proper humility.

The five large power plants in New York City consume approximately 3500 tons of coal per day and of this coal, costing approximately $\$ 11,000$, 60 per cent, or $\$ 6,600$ per day, is lost in the condenser. In effect, we are de- 
liberately dumping $\$ 2,370,000$ per annum into the sea.

Again, of the total fuel burned under our boilers, only about an average of 15 per cent is available for useful work, so that out of our $\$ 4,000,000$ worth of fuel we waste $\$ 3,400,000$ per annum. These large power plants are probably at least three times as efficient as the average factory plant, so that instead of having an average thermal efficiency of 15 per cent, the average of the entire country is in all probability not to exceed 6 per cent.

It will never be possible to recover all the heat in our coal, but there is a wide enough margin between 6 per cent and 100 per cent to encourage our engineers in the hope that they may achieve fame and wealth by discovering some new means of conserving our supply of fuel.

In the meantime, the problem is largely an economic one, for we seem to reach a state in the art in about every decade where the saving of fuel, due to the installation of more efficient apparatus, more than offsets the destruction of capital caused by deliberately scrapping good machinery for the sake of more efficient machinery.

Four years ago, in a vainglorious moment, I attempted to improve upon Tredgold's definition of engineering, and now I feel that I must, in closing, make another attempt at a better definition, which will include efficiency:

Engineering - the art of obtaining the maximum return from the minimum expenditure, of capital and labor, or of the forces and materials of nature.

\section{A. 1. E. E. Meeting in New York, January 10, 1913}

The two hundred and seventy-ninth meeting of the Institute was held in the auditorium of the Engineering Societies Building, New York, Friday evening, January 10, 1913.

President Ralph D. Mershon called the meeting to order at 8:15 o'clock, and then turned the remainder of the technical session over to Mr. Henry G. Stott, chairman of the Power Station
Committee, under whose auspices the meeting was held.

Chairman Stott then called upon Mr. B. G. Lamme, the author of the paper of the evening, entitled High-Speed Turbo-Generators-Designs and Limitations. Mr. Lamme in presenting his paper gave a brief abstract of its objects and scope.

The paper was then discussed in detail by Chairman Stott and Messrs. Henry G. Reist, R. B. Williamson, Philip Torchio, Carl J. Fechheimer, William LeRoy Emmet, Paul M. Lincoln, Peter Junkersfeld, H. M. Hobart, W. L. Waters, Comfort A. Adams, and Allan B. Field. The technical session closed at 10:30 p.m. after much valuable discussion had been presented on the construction and limitations of various types of high-speed turbo-alternators. The members then adjourned to the Institute rooms on the tenth floor where the usual smoker was held.

\section{Recommended for Transfer to the Grade of Member, January 2, 1913}

The following Associates were recommended for transfer to the grade of Member by the Board of Examiners at its regular monthly meeting held on January 2, 1913. Any objection to these transfers should be filed at once with the Secretary:

Hart, Percy E., Estimating Engineer, Canadian General Electric Co., Toronto, Ont.

Street, George T., Electrical Superintendent, San Domingo Light \& Power Co., Puerta Plata, S. D.

\section{Transferred to Grade of Fellow, January 10, 1913.}

The following were transferred to the grade of Fellow of the Institute at the meeting of the Board of Directors on January 10, 1913.

Keith, Alexander E., Chief Engineer, Automatic Electric Co., Chicago, IIl.

Lardner, Henry A., Manager, J. G. White \& Co., San Francisco, Cal. 